\title{
Simultaneous assessment of myocardial scar and coronary artery disease by navigator-gated 3D fat-suppressed delayed-enhancement CMR: comparison with 2D delayed-enhancement CMR, $\mathrm{CT}$ and $\mathrm{CAG}$
}

\author{
Yasuo Amano*, Tomonari Kiriyama, Masaki Tachi, Yasuhiro Kobayashi, Tetsuro Sekine, Shinichiro Kumita
}

From 15th Annual SCMR Scientific Sessions

Orlando, FL, USA. 2-5 February 2012

\section{Summary}

The aim of this study was to assess the feasibility of navigator-gated 3D fat-suppressed delayed-enhancement CMR (DE-CMR) for simultaneous assessment of the myocardial scar and coronary artery disease, by comparing with 2D DE-CMR, CT, and CAG.

\section{Background}

Simultaneous assessment of myocardial scar or perfusion reduction and coronary artery stenosis is currently performed by side-by-side comparison or image fusion using coronary CTA and myocardial perfusion study, but the misregistration and differences in spatial resolution between imaging methods can be problematic. A CMR technique that can visualize both myocardial scar and coronary artery disease during a single examination may resolve this problem.

\section{Methods}

Sixteen patients underwent a navigator-gated 3D fatsuppressed DE-CMR using a 3.0T imager. The spatial resolution of this imaging was $1.5 \times 1.25 \times 3.0-3.4 \mathrm{~mm} 3$ before an interpolation. Inversion recovery and spectrally-selective pulses were used to suppress normal myocardial and epicardial fat signals, respectively. The ability of the navigator-gated 3D fat-suppressed DECMR to detect myocardial scar was compared with that of 2D DE-CMR. The signal reduction of coronary artery on the 3D DE-CMR was compared with calcified plaques on CT $(\mathrm{n}=13)$ and significant stenosis $(>75 \%)$ on CAG $(n=8)$. The relationship between myocardial scar and coronary arteries was also assessed in six patients with ischemic cardiomyopathies.

\section{Results}

Twenty-five myocardial scars on 2D DE-CMR, 66 coronary calcified lesions on CT, and six coronary stenoses on CAG were investigated in 16 patients. The navigatorgated 3D fat-suppressed DE-CMR detected 25 (92.6\%) scars, $43(65.1 \%)$ arterial signal reduction, and three $(50 \%)$ coronary artery stenoses. When excluding the coronary arteries that were affected by respiratory artifacts, $84.3 \%$ of coronary artery diseases were detected by the 3D-CMR. This imaging showed the diffuse stenoses of coronary arteries, comparable to diffuse calcified plaques, in the patients with ischemic cardiomyopathy.

\section{Conclusions}

Navigator-gated 3D fat-suppressed DE-CMR was feasible for simultaneous assessment of the myocardial scar and coronary arteries with calcified plaques.

\section{Funding}

No disclosure for this presentation.

Published: 1 February 2012 




Figure 1 Navigator-gated 3D fat-suppressed DE-CMR shows myocardial scar following infarction.

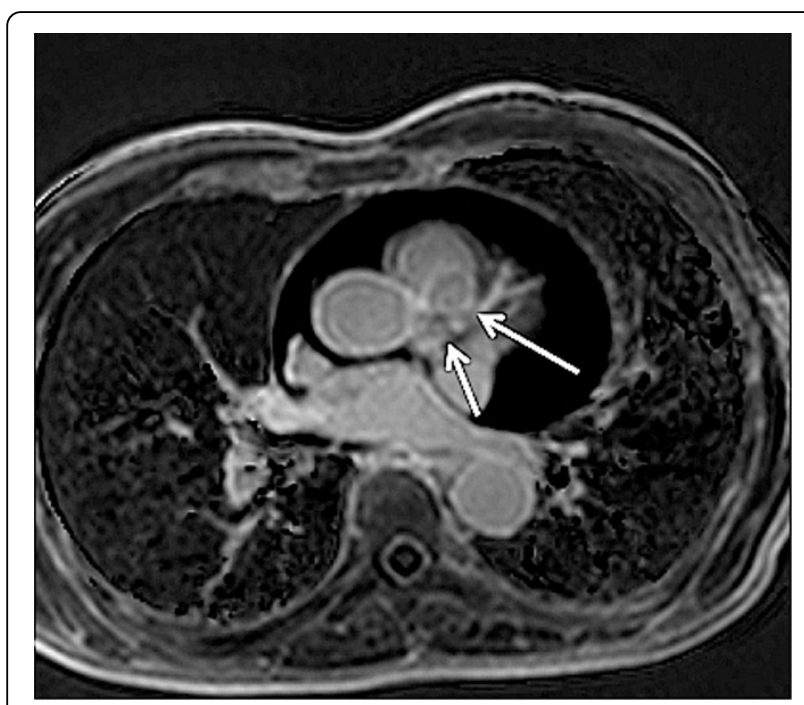

Figure 2 Navigator-gated 3D fat-suppressed DE-CMR shows signal reduction of coronary arteries simultaneously.
doi:10.1186/1532-429X-14-S1-P302

Cite this article as: Amano et al: Simultaneous assessment of

myocardial scar and coronary artery disease by navigator-gated 3D fatsuppressed delayed-enhancement CMR: comparison with 2D delayedenhancement CMR, CT and CAG. Journal of Cardiovascular Magnetic Resonance 2012 14(Suppl 1):P302.

\section{Submit your next manuscript to BioMed Central} and take full advantage of:

- Convenient online submission

- Thorough peer review

- No space constraints or color figure charges

- Immediate publication on acceptance

- Inclusion in PubMed, CAS, Scopus and Google Scholar

- Research which is freely available for redistribution 